\title{
Diagnostics of the depth of digitalization of HR management
}

\author{
Tatiana Gaponenko ${ }^{1 *}$, Anastasia Malkhasyan ${ }^{1}$, Nikolay Filin $^{2}$, and Raykhana Bulatova ${ }^{2}$ \\ ${ }^{1}$ Don State Technical University, 344000, Rostov-on-Don, Russia \\ ${ }^{2}$ Rostov State University of Economics, 344002, Rostov-on-Don, Russia
}

\begin{abstract}
The purpose of the article is to develop a methodology which assesses the level of digitalization of HR management, to identify the reasons for the gap between the actual achieved level and the desired one, and to justify management decisions related to the introduction of digital technologies. The methodology involves diagnostics of the level of digitization of HR-management in three aspects: digital competence of personnel, digital workplace, digital management system. A combined method has been proposed for the diagnosis of staff digital competences: self-diagnostic and manager's assessment on a single scale, followed by a comparison of the results. A coefficient method is proposed for estimating a digital workplace and a digital control system. The resulting conclusion on the level of digitization of an organization's HR management is based on the benchmarking method. The implementation of measures to increase the level of digitalization of HR management, adopted on the basis of the conducted diagnostics, will allow the organization to maintain and to increase its competitive advantages by developing the necessary professional qualities of employees, the best organization of personnel management in the conditions of digitalization.
\end{abstract}

\section{Introduction}

By the end of the 20th century and the beginning of the 21st century, significant changes had already taken place in the macro-environment of organizations, associated with the widespread spread of information and communication and digital technologies, their active implementation in the activities of organizations, including in the field of personnel management.The classical paradigm of HR management, the main task of which was to organize labor processes on the basis of its division by functions between individuals, is losing its relevance. The new digitalized HR management setsa main task of ensuring the involvement of personnel in the work activity, divided by projects between teams, while the main resource of labor is not just human capital, but a symbiosis of talents and digital technologies [1]. HR management in the conditions of digitalization is characterized by the following features:

- searching, recruitment selection of personnel for a specific time-limited project rather than a full-time job;

\footnotetext{
*Corresponding author: gaponenko.t@mail.ru
} 
- using social media to select and monitor staff;

- priority is given to workers' abilities such as multitasking, creativity (innovation), speed of work, ability to change quickly, adaptability $[2,3]$;

- digital literacy becomes a prerequisite for employment alongside general and specialized knowledge;

- the usage of messengers (WhatsApp, Telegram, etc.) as the main communication channels of the staff;

- remote employment through collaboration platforms and virtual collaboration tools [4];

- automated personnel document management;

- personalized motivational tools;

- real-time monitoring of labor efficiency using digital technologies [2].

The usage of digital technologies in HR management (Table 1) changes almost all aspects of the personnel management system: personnel requirements, the system of recruitment and selection of personnel, motivation, organization of labor relations, methods and methods of personnel management.It is clear that the changes are taking place, but the methodological basis for managing staff in a digital environment is not yet sufficiently developed. In particular, there are practically no tools to measure the depth of digitalization penetration into the HR management system. This problem is relevant, those organizations that win in the speed of introduction of new products, ideas and solutions get the main competitive advantages today, as digital technologies today are the leading innovations. It is important for modern organizations to adequately assess their competitive positions in the field of HR management in order to see their weaknesses, identify problems and form prospects for increasing their capabilities.

Table 1.The usage of digital technologies in HR management

\begin{tabular}{|l|l|}
\hline $\begin{array}{l}\text { Personnel management } \\
\text { subsystem }\end{array}$ & Information and digital technologies \\
\hline $\begin{array}{l}\text { - general and line } \\
\text { management }\end{array}$ & $\begin{array}{l}\text { HRM systems, HR modules of integrated software } \\
\text { systems (ERP level), strategic business management } \\
\text { systems (BPM) }\end{array}$ \\
\hline $\begin{array}{l}\text { - personnel planning and } \\
\text { marketing }\end{array}$ & $\begin{array}{l}\text { Digital Communication Tools (social networks), Jungle } \\
\text { Jobs Stafory, }\end{array}$ \\
\hline $\begin{array}{l}\text { - selection and } \\
\text { recruitment }\end{array}$ & $\begin{array}{l}\text { E-Staff Recruiter, Friend Work Recruiter, Amazing } \\
\text { Hiring, GoRecruit } \\
\text { VCV, Skillaz, Pre-Interview, digital resume screening }\end{array}$ \\
\hline - labor relations & $\begin{array}{l}\text { Skill Tech, Retra Tech, SHL, Talent Q, Cut-e, Kenexa, } \\
\text { 1C: Psychodiagnostics, Croco Time, Info Watch Traffic } \\
\text { Monitor, Secure Tower }\end{array}$ \\
\hline $\begin{array}{l}\text { - personnel development } \\
\text { personnel behavior } \\
\text { motivation management }\end{array}$ & SuccessFactors oт SAP, Workday \\
\hline $\begin{array}{l}\text { social development } \\
\text { management }\end{array}$ & $\begin{array}{l}\text { Corporate social networks such as Jive, NPeope, } \\
\text { Pryaniky }\end{array}$ \\
\hline
\end{tabular}

Considering the changes in the field of personnel management associated with the development of information technologies and digitalization, we can distinguish three areas of diagnostics: digital labor resources, digital workplace, digital personnel management.

Diagnostics of digital resources involves the assessment of digital competencies of personnel, first of all, it is the diagnosis of digital literacy. The problem of measuring digital literacy is already the subject of many studies, in particular, the PIAAC and TALIS 
[5-8] models are widely known and used, the European project Erasmus + "Digital Skills Accelerator" [9] is being implemented. In Russia, the Research Institute "Higher School of Economics" has developed a unified model of digital literacy of the population, and also annually tests the population to calculate the digital literacy index of the population. The mentioned methods of measuring digital literacy of the population can be adapted for business when it is necessary to assess special professional competencies, but this requires investment on the part of the customer, time to adapt the methodology, testing and processing the results, and today many enterprises, especially small and medium-sized businesses, lack free funds for investment, while they need to assess their fitness to work in the digital economy. Therefore, it is important to develop methods that are clear, simple and accessible to any object. In addition, the field of diagnostics of the digital workplace and the digital personnel management system as a whole is practically unexplored, and these aspects are important for modern organizations to develop a development strategy, select priority investment areas.

The concept of digital competencies of personnel is widely described in the work [10]. The growing demand for digital skills is discussed in the study [11], where it is noted that the increase in digital competencies of personnel is one of the reasons for the subsequent explosive growth of the company.However, defining the digital competencies of the staff is not enough for effective management. There is a need for a comprehensive assessment of the results of the digitization of personnel management as well as the effectiveness of changes $[12,13]$.

All this defines the purpose of this article - to develop a methodology that allows to assess the level of digitization of HR-management, to identify the reasons for the gap between what is actually achieved and what is needed, and to provide justification for management decisions related to the implementation of digital technologies.

\section{Materials and methods}

The proposed methodology for diagnosing the depth of digitalization of HR management considers three aspects: digital labor force, digital workplace, digital personnel management. It is implemented in the following sequence.

Stage I. Collecting information for calculating HR management digitalization indicators:

- creating a list of common, complementary, and professional digital competencies for each position held;

- self-diagnosis by personnel of the level of proficiency in the relevant digital competencies;

- the manager's assessment of the level of subordinates' possession of the relevant digital competencies;

- the final conclusion about the level of each employee's proficiency in the relevant digital competencies by comparing the results of self-diagnosis and evaluation of the manager and, if the results differ, choosing the lowest level;

- collection of information for the calculation of indicators that characterize the digitalization of workplaces and HR management systems;

- calculation of the share of employees with digital competencies at the general, complementary and professional level;

Stage II. Calculation of diagnostic indicators that characterize the digitalization of workplaces and HR management systems:

- calculation of the share of employees with digital competencies at the general, complementary and professional level; 
- calculation of indicators that characterize the digitalization of workplaces;

- calculation of indicators that characterize the digitalization of the HR management system.

Stage III. Justification of the base for comparing indicators and determining the deviations of the actually achieved level of digitalization of the HR management of the organization from the desired one, determined by the selected comparison base.

Stage IV. Determining the reasons for deviations of the actual level of indicators from the desired one.

Stage V. Development of measures to increase the level of digitalization of the organization's HR management.

Stage VI. Implementation of activities.

Diagnostics of digital labor resources involves identifying the degree of possession of digital competencies by personnel (figure 1), the description of which is presented on the basis of the works $[5,10,14]$.

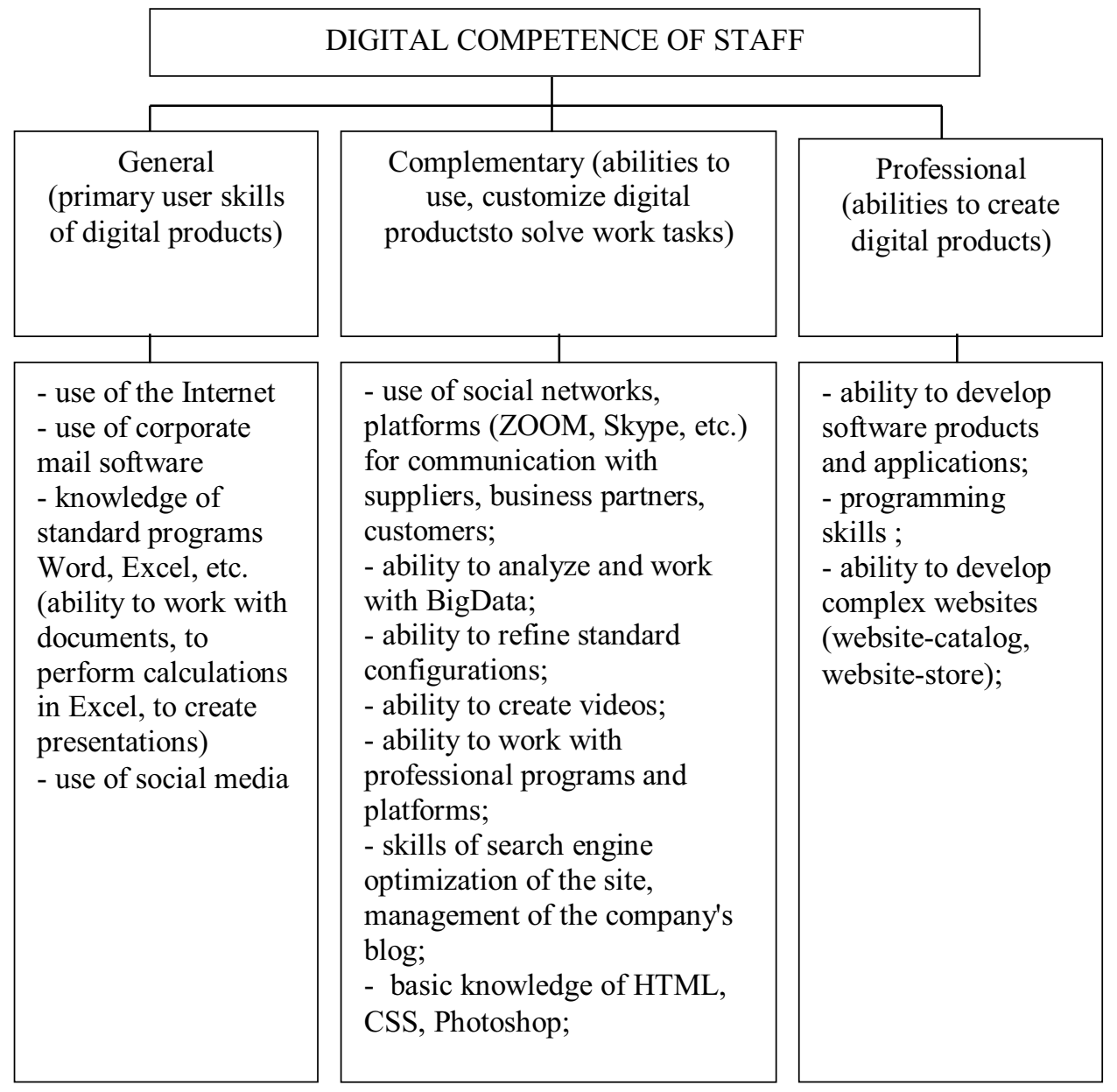

Fig. 1. Digital competence of staff

It is proposed to use a combined diagnostic method: self-diagnosis, when the employee himself evaluates the degree of possession of digital competencies on a special scale (Table 2 ), as well as the manager's assessment of the employee's level of digital competence 
proficiency on the same scale. Where self-assessment and evaluation are different, managers are encouraged to focus on less evaluation.

Table 2. Scale for self-assessment/assessment of the level of digital competence proficiency

\begin{tabular}{|c|c|}
\hline $\begin{array}{c}\text { Proficiency } \\
\text { level }\end{array}$ & Description \\
\hline 0 & I don't have any/Does not have any \\
\hline 1 & $\begin{array}{r}\text { I partially have some, but I rarely use it in my work/he or she has } \\
\text { some, but rarely uses itin his or her work }\end{array}$ \\
\hline 2 & $\begin{array}{c}\text { I am confident in my digital skills, I use it in my workoccasionally } \\
\text { (from time to time) / he or she is confident in his or her digital skills, } \\
\text { he or she uses it in his or her workoccasionally (from time to time) }\end{array}$ \\
\hline 3 & $\begin{array}{c}\text { I have excellent digital skills and constantly use it in my work/he or } \\
\text { she has excellent digital skills and constantly uses it in his or her work }\end{array}$ \\
\hline
\end{tabular}

The degree of digital competence of the staff can be determined using the following indicators:

- percentage of employees who have sufficient general digital competencies (primary user skills);

- the proportion of employees who have sufficient complementary digital competencies. These employees must have the ability to use and refine a digital product. This indicator can be calculated separately for those personnel groups where narrow complementary digital competencies are needed (marketers, programmers, analysts, recruiters, accountants, etc.);

- the proportion of employees who have sufficient digital competencies at the professional level (the ability to develop a digital product independently).

Based on the judgment about the share of employees with a certain level of digital competencies, it is proposed to give the following verbal description of the level of digitalization of the organization's workforce as a whole:

- below 0,31 - low level;

- 0,31-0,65 - medium level;

- $0,66-0,75$ - sufficient level;

- 0,76-0,9 - high level;

- $\quad$ от 0,91 - very high level.

The next object of diagnostics - digital workplaces - is evaluated according to the degree of equipment of workplaces with devices and software that allow implementing digital competencies.

Diagnostics of digital control systems involves determining the degree of control automation - complete, partial. This is determined by the presence (or absence) of a unifying, coordinating software product.

The author's system of indicators for the diagnosis of HR management is presented in figure 2 .

Some of the proposed indicators require clarification, such as the percentage of employees who influence decision-making. The implementation of this indicator in the system is due to the fact that one of the properties of the digital economy is choaccration management without managers, respectively, the digital organization of management is characterized by a reduction in management and an increase in the number of people (ideally all network participants)which are taken into account in the decision-making.

An important component of the HR Management Digitization Diagnostic Tool is the Benchmarking Framework, which directly assesses how deep an organization's performance can be recognized, how different it is from competitors in this respect. 


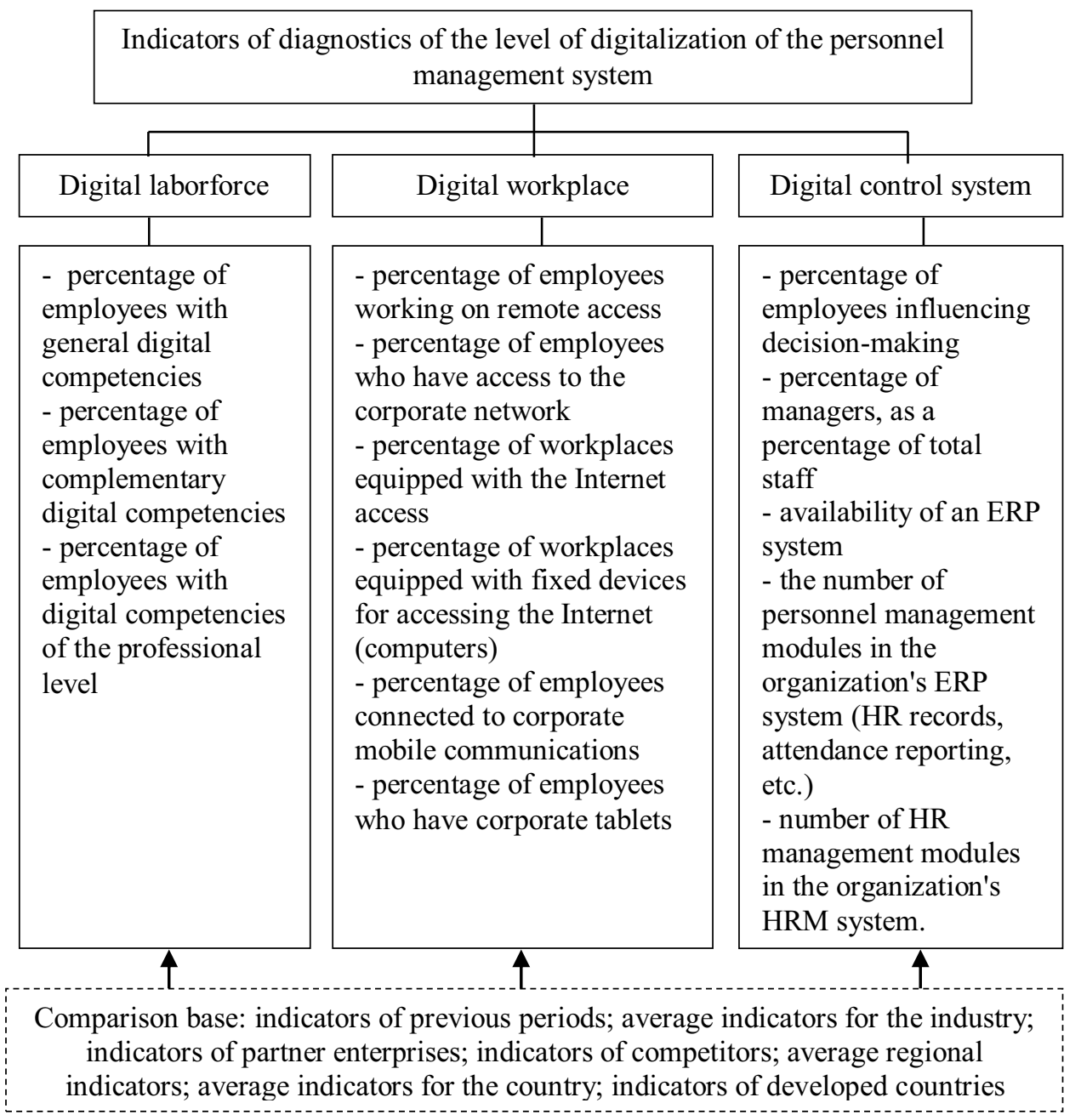

Fig. 2. System of indicators for the diagnosis the level of digitalization of the organization's personnel management

Figure 2 offers a list of possible databases for comparing indicators, they are arranged by priority. First of all, a comparison is made with the previous level, and then (or if there is no own base for comparison), the average indicators for the industry, indicators of partner enterprises, competitors, indicators for the region, country or world are taken as a basis. The choice of the base for comparison is determined by the purpose of the diagnosis, the availability of the necessary information. A significant role in the formation of the information base is played by the development of the cluster environment of the region $[15,16]$.

\section{Results}

The proposed method was tested on the example of a small trade organization with a staff of 16 people. The results of measuring the digital competencies of the staff are presented in 
Table 4. The data of self-assessment and evaluation almost coincided, with different levels of assessment, it was suggested to focus on the smaller of the evaluated ones.

Table 3. Results of measuring digital competencies of personnel

\begin{tabular}{|l|c|c|c|c|c|c|}
\hline \multirow{2}{*}{\multicolumn{1}{|c|}{ Position }} & \multicolumn{7}{c|}{ Digital competencies } \\
\cline { 2 - 8 } & \multicolumn{2}{|c|}{ General } & \multicolumn{2}{c|}{ Complementary } & \multicolumn{2}{c|}{ Professional } \\
\cline { 2 - 7 } & $\mathrm{S}$ & $\mathrm{M}$ & $\mathrm{S}$ & $\mathrm{M}$ & $\mathrm{S}$ & $\mathrm{M}$ \\
\hline Director & 3 & 3 & 2 & 2 & 1 & 1 \\
\hline Head accountant & 3 & 3 & 2 & 2 & 1 & 1 \\
\hline Office manager & 3 & 3 & 2 & 2 & 0 & 0 \\
\hline Sales manager & 3 & 3 & 3 & 2 & 0 & 0 \\
\hline Sales manager & 3 & 3 & 2 & 2 & 0 & 0 \\
\hline Sales manager & 3 & 3 & 2 & 2 & 0 & 0 \\
\hline Sales manager & 3 & 3 & 2 & 2 & 0 & 0 \\
\hline Sales manager & 3 & 3 & 2 & 2 & 0 & 0 \\
\hline Driver & 1 & 1 & 0 & 0 & 0 & 0 \\
\hline Operator & 3 & 3 & 1 & 1 & 0 & 0 \\
\hline Operator & 3 & 3 & 1 & 1 & 0 & 0 \\
\hline Goods manager & 2 & 2 & 1 & 1 & 0 & 0 \\
\hline Warehouse manager & 3 & 3 & 1 & 1 & 0 & 0 \\
\hline Storekeeper & 1 & 1 & 0 & 0 & 0 & 0 \\
\hline Storekeeper & 0 & 1 & 0 & 0 & 0 & 0 \\
\hline Stevedore & 0 & 0 & 0 & 0 & 0 & 0 \\
\hline
\end{tabular}

It is proposed to consider the zero and the first level as insufficient in order to recognize the presence of the necessary digital competencies in a particular employee. The importance of digital competencies for an employer begins with the second level of proficiency (a sufficient degree of proficiency). Based on the obtained estimates, taking into account the sufficiency of the level of proficiency, we will assess the degree of digitalization of the personnel of the organization under study (Table 4). Since the proposed methodology has not yet been used in the organization, there is no information for comparison with previous periods. Therefore, at the moment, it is possible to evaluate only the results of the primary diagnosis and their significance for a particular organization. A database on the level of digitalization of partner enterprises, competitors, and regional enterprises has not yet been formed, since there was no methodology to assess this level.

Table 4. Indicators of the organization's digital workforce

\begin{tabular}{|c|c|c|}
\hline Indicator & $\begin{array}{c}\text { Value based on } \\
\text { the results of the } \\
\text { primary } \\
\text { diagnosis }\end{array}$ & Conclusion \\
\hline $\begin{array}{c}\text { Percentage of employees } \\
\text { with general digital } \\
\text { competencies }\end{array}$ & 0.75 & A fairly high level of proficiency \\
\hline $\begin{array}{c}\text { Percentage of employees } \\
\text { with complementary } \\
\text { digital competencies }\end{array}$ & 0.5 & $\begin{array}{c}\text { Average level of proficiency. It is } \\
\text { necessary to increase the level of } \\
\text { digital technology proficiency } \\
\text { according to the held position }\end{array}$ \\
\hline Percentage of employees & 0 & A lack of employees with digital \\
\hline
\end{tabular}




\begin{tabular}{|c|c|c|}
\hline $\begin{array}{c}\text { with digital } \\
\text { competencies of the } \\
\text { professional level }\end{array}$ & competencies at the professional level. \\
\hline
\end{tabular}

The lack of employees with digital competencies at the professional level can serve as a serious obstacle to development in the digital economy due to the lack of specialists who are able to create digital products for the use of the organization's activities.

The results of diagnostics of the digital workplace and the digital personnel management system of the organization under study are presented in Tables 5,6.

Table 5. Digital workplace diagnostic indicators

\begin{tabular}{|c|c|c|}
\hline Indicator & $\begin{array}{c}\text { Value based on } \\
\text { the results of the } \\
\text { primary } \\
\text { diagnosis }\end{array}$ & Conclusion \\
\hline $\begin{array}{c}\text { Percentage of employees } \\
\text { working on remote } \\
\text { access }\end{array}$ & 0.5 & $\begin{array}{c}\text { A high percentage of employees } \\
\text { working on remote access is connected } \\
\text { with the specifics of trading activities } \\
\text { and the need for constant } \\
\text { communication with customers }\end{array}$ \\
\hline $\begin{array}{c}\text { Percentage of employees } \\
\text { who have access to the } \\
\text { corporate network }\end{array}$ & 0.55 & $\begin{array}{c}\text { Low percentage of employees involved } \\
\text { in corporate informationspace }\end{array}$ \\
\hline $\begin{array}{c}\text { Percentage of workplaces } \\
\text { equipped with the } \\
\text { Internet access }\end{array}$ & 0.31 & $\begin{array}{c}\text { A low level, since remotely employed } \\
\text { employees (sales managers) have } \\
\text { access to the Internet from their own } \\
\text { devices (not corporate ones) }\end{array}$ \\
\hline $\begin{array}{c}\text { Percentage of workplaces } \\
\text { equipped with fixed } \\
\text { devices for accessing the } \\
\text { Internet (computers) }\end{array}$ & 0.56 & $\begin{array}{c}\text { The medium level of equipment, since } \\
\text { remotely employed employees (sales } \\
\text { managers) have access to the Internet } \\
\text { from their own devices (not corporate } \\
\text { ones) }\end{array}$ \\
\hline $\begin{array}{c}\text { Percentage of employees } \\
\text { connected to corporate } \\
\text { mobile communications }\end{array}$ & 0.19 & $\begin{array}{c}\text { All employees are connected to the } \\
\text { corporate tariff plan }\end{array}$ \\
\hline $\begin{array}{c}\text { Percentage of employees } \\
\text { who have non-stationary } \\
\text { portable) devices for } \\
\text { accessing the Internet }\end{array}$ & stationary or from thein own devices \\
\hline
\end{tabular}

Table 6. Diagnostic indicators of the digital control system

\begin{tabular}{|c|c|c|}
\hline Indicator & $\begin{array}{c}\text { Value based on } \\
\text { the results of the } \\
\text { primary } \\
\text { diagnosis }\end{array}$ & Conclusion \\
\hline $\begin{array}{c}\text { Percentage of employees } \\
\text { influencing decision- } \\
\text { making }\end{array}$ & 0.13 & $\begin{array}{c}\text { Two employees(a director anda } \\
\text { headaccountant) influence decision- } \\
\text { making }\end{array}$ \\
\hline $\begin{array}{c}\text { Percentage of managers, } \\
\text { as a percentage of total } \\
\text { staff }\end{array}$ & 0.19 & $\begin{array}{c}\text { Three managers - Director, Head } \\
\text { Accountant, Warehouse manager }\end{array}$ \\
\hline
\end{tabular}




\begin{tabular}{|c|c|c|}
\hline $\begin{array}{c}\text { Availability of an ERP } \\
\text { system }\end{array}$ & No availability & $\begin{array}{c}\text { There is no unified resource planning } \\
\text { system }\end{array}$ \\
\hline $\begin{array}{c}\text { The number of personnel } \\
\text { management modules in } \\
\text { the organization's ERP } \\
\text { system }\end{array}$ & 3 & $\begin{array}{c}\text { Modules "Employee accounting and } \\
\text { HR records management", } \\
\text { "Renumeration its calculations", } \\
\text { "Reporting and analytical processes" }\end{array}$ \\
\hline
\end{tabular}

\section{Discussion of the results}

On average, the level of digitalization of the workplace in the organization under study is medium, and the level of digitalization of management processes is low. To increase the level of digitalization of personnel management in the organization under study, it is necessary to strive for the goal-the development of digital competencies of personnel and access to leadership positions among the nearest competitive environment in terms of digitalization of HR management.

To achieve this goal, the organization is recommended to:

- increase the share of employees with complementary digital competencies to $75 \%$. This can be done both by hiring specialists with high-level complementary digital competencies (content manager, Internet marketer), and by developing new complementary digital competencies (analysis of large amounts of information, analysis of Internet sales, traffic, etc.).The organization currently employs five sales managers with sufficient complementary digital competencies. However, if you move the competitive activity to the Internet the need for sales managers will be reduced, and will increase the need for staff with professional digital competence: skills in programming (website designing, programming, interactive components, testing their performance, ensuring fast loading site in a browser, etc.), website's text content (text writing, layout, quality pictures of goods, etc.), website promotion in search engines Yandex and Google (SEO), development, hosting, analysis of the effectiveness of contextual advertising. This means there will be changes in the staff structure, as the need for specialists with new digital and knowledge and skills increases, and the need for sales managers decreases, so we can expect a decrease in the number of sales managers in this organization and an increase in employees who ensure the operation of the site and online promotion of goods;

-attract specialists with digital competencies at the professional level, and increase the share of employees with professional digital competencies to $10-12 \%$;

- increase the number of human resources management modules in the organization's ERP, which will provide additional tools for staff and performance analysis and betterinformed management decisions.

\section{Conclusion}

The article developed methodological recommendations on diagnostics of depth of HRmanagement digital organization.It allows to identify how the organization's workforce, jobs, and overall personnel management system meet the modern requirements of the digital economy. Lack of staff skills in digital competencies, outdated methods of labor organization and personnel management systems can lead an organization to become less competitive due to low management efficiency. The proposed method is simple and accessible, does not require significant financial investments, and then has a great potential for application. It is recommended for use primarily by small and medium-sized businesses, with a low number of staff, as the methods used in the methodology for measuring digital competencies of personnel may be ineffective with a large number of staff. Experimental 
results of the implementation of the proposed methodology were obtained, which are essential for the development of the theory and practice of the organization's management. According to the research results, the proposed methodology provides managers with sufficient information on such an important issue as the digitalization of HR management, allows them to identify existing problems and the area of their occurrence, and therefore contributes to the development of sound management decisions that provide the organization with competitive advantages in the new economic formation.

\section{References}

1. C.E. Connelly, C.Fieseler, M.Černe, S.R. Giessner, S.I Wong, Human Resource Management Review 31 (1), 100762 (2021). doi: 10.1016/j.hrmr.2020.100762

2. D.Minbaeva, Human Resource Management Review 11, 100820 (2020). doi: 10.1016/j.hrmr.2020.100820

3. K.Barmuta, O.Grishchenko, E3S Web of Conferences 175, 08003 (2020). doi:10.1051/e3sconf/202017508003

4. T. Gaponenko, S. Muradova, V. Litvinova E3S Web of Conferences 175, 15003 (2020). doi:10.1051/e3sconf/202017515003

5. R. Hämäläinen, K. Nissinen, J. Mannonen, J. Lämsä, K. Leino, M. Taajamo, Computers in Human Behavior 117, 106672 (2021). doi: 10.1016/j.chb.2020.106672

6. B. Ertl, A. Csanadi, C. Tarnai, International Journal of Educational Development 78, 102259 (2020). doi: 10.1016/j.ijedudev.2020.102259

7. S.S.Zilian, L.S. Zilian, Technology in Society 63, 101397 (2020). doi: 10.1016/j.techsoc.2020.101397

8. Kuan-Yu Jin, Frank Reichert, L.P. Cagasan Jr., Jimmy de la Torre, Nancy Law Computers \& Education 157, 103968 (2020). doi: 10.1016/j.compedu.2020.103968

9. Przemysław Różewski, Magdalena Kieruzel, Tomasz Lipczyński, Marcin Prys, Miguel-Angel Sicilia, Elena García-Barriocanal, Salvador Sánchez-Alonso, Canice Hamill, Carme Royo, Francesca Uras, Procedia Computer Science 14, 159, 2304-2312 (2019). doi: 10.1016/j.procs.2019.09.405

10. Maren Oberländer, Andrea Beinicke, Tanja Bipp, Computers \& Education 146,103752 (2020). doi: 10.1016/j.compedu.2019.103752

11. Elena Shakina, Petr Parshakov, Artem Alsufiev, Technological Forecasting and Social Change 162,120405 (2020) doi: 10.1016/j.techfore.2020.120405

12. Yue Wang, Microprocessors and Microsystems 7, 103427 (2020). doi: 10.1016/j.micpro.2020.103427

13. Anand Sengupta, Shweta Lalwani, Shubham Goswami, Prateek Srivastava, Materials Today: Proceedings 16, (2020). doi.org/10.1016/j.matpr.2020.10.875

14. André Ribeiro, António Amaral, Teresa Barros, Procedia Computer Science 181, 803810 (2021). doi: 10.1016/j.procs.2021.01.233

15. Svetlana Ugrimova, Natalya Andreeva, Tatyana Tuchkanen, E3s Web of Conferences 175, 06003 (2020). doi: 10.1051/e3sconf / 202017506003.

16. Vladimir Mazur, Karine Barmuta, Sergey Demin, Evgeny Tikhomirov, Maxsim Bykovskiy, International Journal of Economics and Financial 6 (1S), 270-274, (2016). http://www.econjournals.com/index.php/ijefi/article/view/2397/pdf 